Vol. 2 | No. 3 | 2021 | Hal. 221-226

\title{
LAHAN PEKARANGAN SEBAGAI KAWASAN RUMAH PANGAN LESTARI (KRPL):UPAYA PENINGKATAN NILAI FUNGSI LAHAN DENGAN SISTEM VERTIKULTUR
}

\author{
Sugiarto*, Melyana Febryantari Wardana, Dwi Ratna Ningsih, Muhammad Zain, \\ Jumrotin Nur Aini \\ Fakultas Pertanian, Universitas Islam Malang \\ *korespondensi email: sugiartounisma9@gmail.com
}

\begin{abstract}
ABSTRAK
Hasil lahan pekarangan di berbagai wilayah tergolong kurang optimal dikarenakan pola pengelolaan yang kurang sempurna. Tujuan untuk meningkatkan potensi lahan pekarangan dengan sistem vertikultur. Kegiatan pengabdian kepada mayarakat ini dilaksanakan di Desa Raci Tengah, Kecamatan Sidayu, Kabupaten Gresik pada tahun 2021. Metode pengambilan data menggunakan Convinience Sampling dengan pendekatan Participation Action Research (PAR). Data yang digunakan meliputi data primer dan data sekunder. Adapun analisis data menggunakan skala likert dengan jumlah sampel 94 responden. Ditinjau dari hasil dan pembahasan pengelolaan lahan pekarangan sebagai Kawasan Rumah Pangan Lestari (KRPL) di Desa Raci Tengah dengan sistem vertikultur mampu meningkatkan perbaikan pendapatan masyarakat per tahunnya 33,3\% dengan rata-rata pendapatan sebesar $R p 450.000-R p$ 600.000/bulan dan diharapkan masyarakat dapat mengembangkan lebih lanjut untuk dapat mewujudkan ketahanan pangan secara mandiri dan meningkatkan kesejahteraan rumah tangga.
\end{abstract}

Kata Kunci: vertikultur; KRPL; ketahanan pangan

\section{PENDAHULUAN}

Desa Raci Tengah, Kecamatan Sidayu, Kabupaten Gresik mayoritas penduduknya bermatapencaharian sebagai petani. Luas total lahan sawah Desa Raci Tengah adalah 47 ha sedangkan luas total lahan pekarangan seluas 67,43 ha (BPS, 2021). Ditinjau dari luas lahan pekarangan yang dimiliki dapat menghasilkan pendapatan tambahan jika dikelola secara profesional. Penanganan dimaksudkan agar lahan pekarangan mempunyai nilai tambah. Pemanfaatan lahan pekarangan untuk pengembangan industri rumah tangga merupakan salah satu alternatif untuk mewujudkan kemandirian ekonomi rumah tangga (Kurnianingsih et al., 2013). Peranan dan pemanfaatan pekarangan bervariasi di antara suatu wilayah dengan wilayah lainnya, dimana hal ini juga dipengaruhi oleh tingkat kebutuhan, sosial budaya, pendidikan masyarakat, maupun faktor fisik dan ekologi wilayah setempat (Khomah \& Fajarningsih, 2016). Menurut Rahayu (2005) pekarangan jika dikelola dengan baik akan berpotensi menambah penghasilan keluarga, sehingga peranan lahan pekarangan secara tidak langsung mampu mempengaruhi perekonomian rumah tangga.

Pangan adalah kebutuhan dasar masyarakat yang harus terpenuhi (Faqih, 2015; Machfudz et al., 2018). Kondisi terpenuhinya pangan bagi rumah tangga tercermin dari tersedianya pangan yang cukup, baik dari jumlah, mutu, dan aman untuk dikonsumsi. 
Mewujudkan ketahanan pangan diperlukan kemampuan dalam menyediakan pangan secara mandiri dengan memanfaatkan pekarangan pada tingkat rumah tangga. Menurut Saptana et al. (2013) terpenuhinya pangan bagi setiap rumah tangga merupakan tujuan sebagai sasaran dari ketahanan pangan di Indonesia sehingga pemantapan ketahanan pangan dapat dilakukan melalui pemantapan ketahanan pangan pada tingkat rumah tangga.

Menurut Nurholis (2021) Kawasan Rumah Pangan Lestari (KRPL) merupakan pemberdayaan rumah tangga dengan prinsip pemanfaatan pekarangan yang ramah lingkungan yang dirancang sebagai pemenuhan kebutuhan pangan dan gizi keluarga serta diversifikasi pangan berbasis sumber daya lokal. Pemanfaatan lahan pekarangan dapat memberikan berbagai manfaat, meliputi sebagai sumber pangan dan tambahan pendapatan keluarga (Azra et al., 2014). Pemanfaatan lahan pekarangan diperlukan perencanaan yang baik dan sistematis terutama dalam menjaga kelestarian sumberdaya dan meningkatkan kesejahteraan rumah tangga (Sunanti \& Aviory, 2021). Kendala yang dihadapi adalah keterbatasan luas lahan dan sosiodemografi, seperti usia, tingkat pendidikan, dan pengalaman berusahatani. Salah satu alternatif dalam pengelolaan adalah melakukan edukasi kepada masyarakat dengan mengubah teknik budidaya yaitu dengan sistem vertukultur. Vertikultur yaitu teknik bercocok tanam pada lahan sempit dengan memanfaatkan bidang vertikal sebagai tempat bercocok tanam yang dapat dilakukan secara bertingkat.

Upaya menghidupkan kembali nilai fungsi lahan pekarangan dapat dilakukan melalui kegiatan pemberdayaan masyarakat dalam meningkatkan kemandirian, seperti memberikan edukasi vertikultur kepada masyarakat. Kegiatan tersebut untuk mengoptimalkan potensi lahan pekarangan dengan sistem vertikultur dan masyarakat diharapkan berperan aktif dalam mewujudkan ketersediaan, distribusi dan konsumsi pangan, serta meningkatkan kesejahteraan rumah tangga.

\section{METODE}

Kegiatan pengabdian kepada masyarakat ini dilakukan di Desa Raci Tengah, Kecamatan Sidayu, Kabupaten Gresik pada tahun 2021. Pengambilan informasi data diperlukan metode pendekatan kemasyarakat yaitu memakai Participation Action Research (PAR) dan pengambilan data menggunakan teknik Convinience Sampling, yaitu anggota populasi target yang memenuhi kriteria tertentu, seperti kemudahan aksesibilitas, kedekatan geografis, ketersediaan waktu tertentu atau kemauan untuk berpartisipasi. Penentuan sampel menggunakan formulasi slovin, yakni sebagai berikut: Ukuran sampel (n) $=$ Ukuran populasi $(\mathrm{N}) / 1+\left(\mathrm{N} \mathrm{x} \mathrm{e}^{\wedge} 2\right)$, dimana e adalah Margin of error (tingkat kesalahan maksimum 10\%) dan diperoleh jumlah sampel sebanyak 94 responden. Data selanjutnya dianalisis menggunakan skala likert, yang dapat diketahui dengan pemberian skor pada setiap pernyataan, dengan persamaan: Total=T $\mathrm{x}$ Pn. Total jumlah responden yang memilih (T) dan Pilihan angka skor likert (Pn). Nilai indeks (\%) diformulasikan bahwa total tiap kategori yang dijumlahkan untuk setiap pernyataan dibagi dengan skor tertinggi likert $x$ jumlah responden (Y) dikali 100.

\section{HASIL DAN PEMBAHASAN}

Masyarakat Desa Raci Tengah, Kecamatan Sidayu, Kabupaten Gresik, dalam pemanfaatan lahan pekarangan tergolong belum optimal dikarenakan keterbatasan luas lahan. Menurut Badan Pusat Statistik (2021), Desa Raci Tengah memiliki luas lahan pekarangan seluas 67,43 ha. Pola pengelolaan lahan pekarangan dapat dilihat pada Tabel 1, sebagai berikut: 
Tabel 1. Pola Pengelolaan Lahan Pekarangan di Desa Raci Tengah, Sidayu, Gresik

\begin{tabular}{llcc}
\hline \multicolumn{2}{c}{$\begin{array}{c}\text { Teknik Pengelolaan Lahan } \\
\text { Pekarangan }\end{array}$} & $\begin{array}{c}\text { Luas lahan } \\
\text { Pekarangan (Ha) }\end{array}$ & $\begin{array}{c}\text { Pendapatan } \\
\text { (Rp/Bulan) }\end{array}$ \\
\hline \multirow{2}{*}{ Konvensional } & Monokultur (30\%) & 22,47 & $150.000-300.000$ \\
Modern & Polikultur (50\%) & 33,73 & $300.000-450.000$ \\
\hline
\end{tabular}

Mayoritas masyarakat memanfaatkan lahan pekarangan yang dikelola secara konvensional yaitu dengan presentase $80 \%$, yang meliputi pola monokultur sebesar $30 \%$ dan polikultur sebesar 50\%. Pemanfaatan lahan pekarangan dengan sistem vertikultur hanya mencapai 20\%, hal ini dikarenakan masyarakat belum mengetahui teknik atau tata cara dalam budidaya sistem vertikultur. Teknik budidaya vertikultur adalah teknik bubidaya tanaman secara vertikal yang kemudian disusun bertingkat dan tidak memerlukan lahan yang luas. Pemanfaatan teknik ini memungkinkan untuk budidaya dengan memanfaatkan tempat secara efisien.

Berdasarkan data sosiodemografi, yang dapat mempengaruhi masyarakat dalam pengelolaan lahan pekarangan terdapat beberapa aspek, meliputi tingkat usia, pendidikan, pengalaman usahatani, dan pendapatan. Data sosiodemografi dapat dilihat pada Tabel 2.

Tabel 2. Data Sosiodemografi di Desa Raci Tengah, Sidayu, Gresik

\begin{tabular}{lcc}
\hline Data Sosiodemografi & Keterangan & Persentase (\%) \\
\hline Usia & $26-35$ Tahun & 20 \\
& $36-45$ Tahun & 34 \\
& $46-55$ Tahun & 30 \\
$56-65$ Tahun & 11 \\
& $>65$ Tahun & 5 \\
Pendidikan & SD & 16 \\
& SMP & 46 \\
Pengalaman Usahatani & SMA & 32 \\
& Sarjana & 6 \\
& 1-3 Tahun & 18 \\
& 3-5 Tahun & 16 \\
& $5-7$ Tahun & 22 \\
& $7-9$ Tahun & 37 \\
& $>9$ Tahun & 6 \\
\hline
\end{tabular}

Berdasarkan tingkat usia, penduduk yang mengelola lahan pekarangan relatif masih pada usia produktif, yaitu 26-55 tahun. Menurut Simanjuntak dalam Ranti (2009), usia produktif berkisar antara usia 15-54 tahun. Hal ini menunjukkan pada usia produktif sangat mudah diarahkan untuk diberikan inovasi dalam pengelolaan dan kemampuan fisik yang masih mendukung untuk mengelola lahan pekarangan sehingga dapat mewujudkan ketahanan pangan secara mandiri dan dapat meningkatkan kesejahteraan rumah tangga.

Dilihat dari tingkat pendidikan, mayoritas penduduk memiliki tingkat pendidikan akhir adalah SMP dengan persentase 46\%, hal ini menunjukkan bahwa tingkat pendidikan masih relatif rendah, namun dapat didorong oleh masyarakat yang memiliki tingkat pendidikan relatif lebih tinggi. Menurut Nurhayati dan Sahara dalam Ranti (2009), bahwa semakin tinggi tingkat pendidikan seseorang, maka akan cepat tanggap terhadap perkembangan teknologi dan kemampuan seseorang.

Ditinjau dari tingkat pengalaman dalam berusahatani, masyarakat memiliki lama pengalaman usahatani yaitu 7-9 tahun dengan persentase sebesar 37\%, hal ini menunjukkan bahwa pengalaman usahatani juga berpengaruh terhadap optimalisasi pengelolaan lahan pekarangan, walaupun pendidikan akhir relatif rendah tetapi semakin tinggi tingkat 
pengalaman dalam berusahatani dapat pula mendukung pemanfaatan lahan pekarangan secara optimal.

Berdasarkan tingkat pendapatan, rata-rata pendapatan masyarakat mencapai $\mathrm{Rp}$ 150.000 - Rp 450.000 dengan pegelolaan lahan secara konvensional seluas 56,20 ha, meliputi pola monokultur dan polikultur. Rata-rata pendapatan masyarakat yang menggunakan pengelolaan lahan pekarangan sistem budidaya vertikultur dengan lahan seluas 11,23 ha dapat mencapai Rp 450.000 - Rp 600.000, hal ini menunjukkan bahwa dengan menggunakan sistem vertikultur dapat membantu untuk meningkatkan kesejahteraan rumah tangga. Untuk mengetahui hubungan antara pengelolaan lahan pekarangan dengan pendapatan masyarakat, dapat dilihat pada Gambar 1, sebagai berikut:

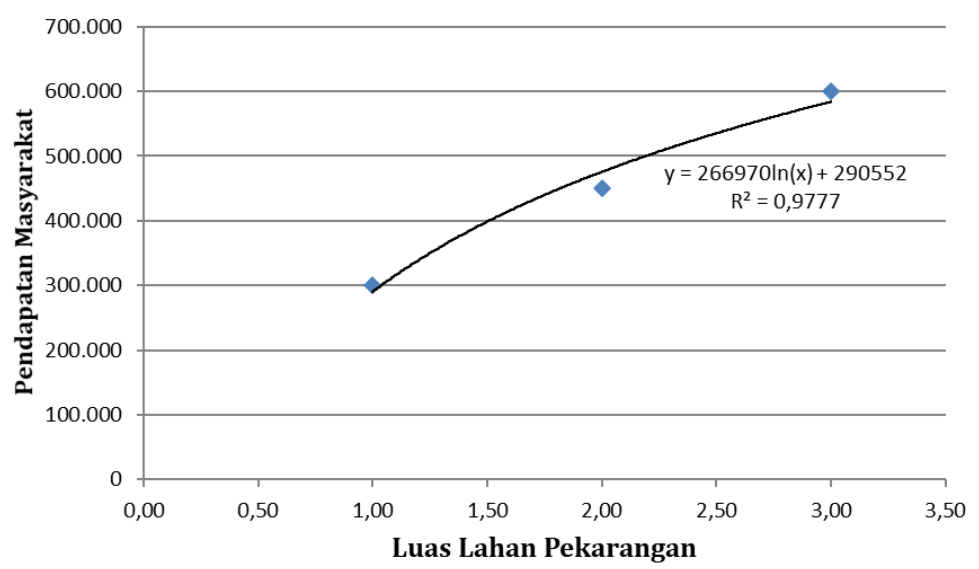

Gambar 1. Korelasi Pengelolaan Lahan Pekarangan dan Pendapatan Masayarakat

Berdasarkan Gambar 1, hubungan (korelasi) antara pengelolaan lahan pekarangan dengan pendapatan masyarakat menghasilkan nilai yaitu $y=266.970 \ln (x)+290.552$ dengan $\mathrm{R} 2=0,9777$, hal ini menunjukkan bahwa masyarakat yang telah menerapkan budidaya sistem vertikultur masih memiliki luas lahan yang relatif rendah, tetapi dapat meningkatkan kesejahteraan rumah tangga, dengan rata-rata pendapatan sebesar Rp 450.000 - Rp 600.000 dibandingkan dengan pengelolaan lahan secara konvensional baik itu dengan pola monokultur maupun polikutur.

Untuk mengetahui preferensi masyarakat mengenai pengelolaan lahan pekarangan, maka peneliti memberikan kuesioner kepada masyarakat yang telah tersaji pada Tabel 3, sebagai berikut:

Tabel 3. Preferensi Masyarakat Desa Raci Tengah, Sidayu, Gresik

\begin{tabular}{lcc}
\hline \multicolumn{1}{c}{ Pernyataan } & Persentase (\%) & Interpretasi \\
\hline $\begin{array}{l}\text { Pemanfataan lahan pekarangan dapat diwujudkan dengan } \\
\text { model Kawasan Rumah Pangan Lestari (KRPL) }\end{array}$ & 90 & Sangat Setuju \\
$\begin{array}{l}\text { Pemanfaatan lahan pekarangan harus dilestarikan untuk } \\
\text { mewujudkan ketahanan pangan }\end{array}$ & 91 & Sangat Setuju \\
$\begin{array}{l}\text { Pemanfaatan lahan pekarangan dapat dilakukan dengan } \\
\text { teknik vertikultur }\end{array}$ & 83 & Setuju \\
$\begin{array}{l}\text { Teknik vertikultur dapat dilakukan dengan berbagai } \\
\text { komoditi, seperti sayuran }\end{array}$ & 83 & Setuju \\
$\begin{array}{l}\text { Hasil panen budidaya dengan teknik vertikultur dapat } \\
\text { dijadikan sebagai peluang usaha } \\
\begin{array}{l}\text { Dengan dijadikannya sebagai usaha dapat meningkatkan } \\
\text { kesejahteraan rumah tangga }\end{array}\end{array}$ & 91 & Sangat Setuju \\
\hline
\end{tabular}


Berdasarkan tabel diatas, masyarakat Desa Raci Tengah beranggapan bahwa optimalisasi lahan pekarangan dalam setiap rumah tangga harus dilestarikan dikarenakan dengan adanya optimalisasi tersebut dapat mewujudkan ketahanan pangan secara mandiri dengan model Kawasan Rumah Pangan Lestari (KRPL) menggunakan teknik vertikultur. Hal ini juga dapat menjadikan peluang usaha bagi setiap rumah tangga dengan memperjualbelikan hasil panen agar dapat meningkatkan kesejahteraan rumah tangga.

Lahan pekarangan di Desa Raci Tengah mayoritas masih menggunakan budidaya secara konvensional dan masih hanya dengan pengetahuan yang dimiliki saja. Penggunaan lahan pekarangan masih belum optimal dikarenakan masyarakat belum mampu untuk mengelola lahan pekarangan dengan baik sehingga dapat menjadi nilai fungsi agar mewujudkan ketahanan pangan dan meningkatkan kesejahteraan rumah tangga. Menurut Kesmayanti (2020), penerapan teknik budidaya vertikultur berfungsi sebagai sumber pangan mandiri dengan metode yang mudah dan modal yang murah dengan memanfaatkan lahan yang sempit menjadi optimal. Penerapan vertikultur dapat mengundang banyak manfaat sebagai sumber pangan, mendukung penghijauan, dan meningkatkan pasokan oksigen bersih yang dihasilkan oleh tanaman.

\section{KESIMPULAN}

Pengelolaan lahan pekarangan sebagai Kawasan Rumah Pangan Lestari (KRPL) di Desa Raci Tengah dengan sistem vertikultur mampu meningkatkan perbaikan pendapatan masyarakat per tahunnya 33,3\% dengan rata-rata pendapatan sebesar Rp 450.000 - Rp 600.000/bulan dan diharapkan masyarakat dapat mengembangkan lebih lanjut untuk dapat mewujudkan ketahanan pangan secara mandiri dan meningkatkan kesejahteraan rumah tangga.

\section{UCAPAN TERIMA KASIH}

Peneliti mengucapkan terima kasih kepada masyarakat Desa Raci Tengah, Kecamatan Sidayu, Kabupaten Gresik yang telah memberikan kesempatan dan dukungan kepada peneliti untuk melakukan dan menyelesaikan kegiatan pemberdayaan masyarakat ini.

\section{DAFTAR RUJUKAN}

Azra, A. L. Z., Arifin, H. S., Astawan, M., \& Arifin, N. H. (2014). Analisis Karakteristik Pekarangan dalam Mendukung Penganekaragaman Pangan Keluarga di Kabupaten Bogor. Jurnal Lanskap Indonesia, 6(2), 1-12. https://doi.org/10.29244/jli.2014.6.2.112

Faqih, A. (2015). Persepsi Anggota Kelompok Tani terhadap Peranan Kelompok Tani di Kecamatan Suranenggala Kabupaten Cirebon Propinsi Jawa Barat. Jurnal Logika, 15(3), 1-18. https://doi.org/10.4135/9781849209403.n73

Kesmayanti, N. (2020). Penyuluhan bertani di lahan sempit perkotaan dengan pertanaman sistem vertikultur. Jurnal Pengabdian Kepada Masyarakat, 1(1), 1-9. https://journal.unbara.ac.id/index.php/abdimu/article/view/660

Khomah, I., \& Fajarningsih, R. U. (2016). Potensi dan Prospek Pemanfaatan Lahan Pekarangan terhadap Pendapatan Rumah Tangga. Procceding Seminar Nasional Peningkatan Kapabilitas UMKM Dalam Mewujudkan UMKM Naik Kelas Pemanfaatan, 155-161.

Kurnianingsih, A., Nusyirwan, Setyati, E. D., \& Syawal, Y. (2013). Optimalisasi Lahan Pekarangan Dengan Budidaya Tanaman Lidah Buaya Yang Berkhasiat Obat Di Desa Purna Jaya Kecamatan Indralaya Utara Kabupaten Ogan Ilir. Jurnal Pengabdian Sriwijaya, 1(1), 21-24. https://doi.org/10.37061/jps.v1i1.1545 
Machfudz, M., Khoiryah, N., \& Hindarti, S. (2018). Pelatihan Penanaman Prilaku Konsumsi Singkong Dan Responsi Masyarakat. Jurnal Inovasi Hasil Pengabdian Masyarakat (JIPEMAS), 1(2), 119-128. https://doi.org/10.33474/jipemas.v1i2.1516

Nurholis. (2021). Kawasan Rumah Pangan Lestari sebagai Upaya Peningkatan Ketahanan Pangan Masyarakat Pada Masa Pendemi Covid-19. Jurnal Ilmiah Pangabdhi, 7(1), 710. https://doi.org/10.21107/pangabdhi.v7i1.8635

Rahayu, M. (2005). Keanekaragaman Tanaman Pekarangan dan Pemanfaatannya di Desa Lampeapi, Pulau Wawoni - Sulawesi Tenggara. Jurnal Teknologi Lingkungan, 6(2), 360-365. https://doi.org/10.29122/jtl.v6i2.338

Ranti, D. (2009). Peranan Program Pemberdayaan Pertanian Lembaga Amilzakat (Laz) Swadaya Ummah Terhadap Peningkatan Pendapatan Petani Dl Kelurahan Kulim Kecamatan Tenayan Raya Kota Pekanbaru [Universitas Riau]. http://repository.unri.ac.id/xmlui/handle/123456789/7258

Saptana, Sunarsih, \& Friyatno, S. (2013). Prospek Model-Kawasan Rumah Pangan Lestari (MKRPL) Dan Replikasi Pengembangan KRPL. Forum Penelitian Agro Ekonomi, 31(1), 67-87. https://doi.org/10.21082/fae.v31n1.2013.67-87

Sunanti, T., \& Aviory, K. (2021). Pemanfaatan pekarangan dalam upaya mendukung ketahanan pangan keluarga. Jurnal Inovasi Hasil Pengabdian Masyarakat (JIPEMAS), 4(3). https://doi.org/10.33474/jipemas.v4i3.10365 